Celal Bayar University Journal of Science

\title{
Static Analysis of the Slotted Upper Plate of Low Pressure Casting Machine
}

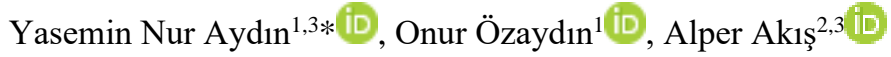 \\ ${ }^{1}$ Cevher Wheels / R\&D Department, İzmir, Turkey \\ ${ }^{2}$ Numesys Inc. / Mechanical Business Unit, İzmir, Turkey \\ ${ }^{3}$ Manisa Celal Bayar University /Department of Mechanical Engineering, Manisa, Turkey \\ *yaseminnuraydinn@gmail.com \\ *Orcid: 0000-0001-7083-2329
}

Received: 12 August 2020

Accepted: 11 March 2021

DOI: $10.18466 /$ cbayarfbe.779687

\begin{abstract}
In this study, the process improvement / Kaizen case study of a casting mold set-up process, was examined. The aim of this work was reducing the set-up time and improving ergonomic conditions. Since existing operating conditions cause a waste of time, an air impact wrench had to be used in the mold assembly process. To be able to use the air impact wrench, a new geometry had to implemented on casting mold and this design change was analyzed in ANSYS software to avoid a failure in working conditions. It was concluded that the maximum stress on the mold was not at a level where it would cause failure. After the initial geometry improvement process, a further ANSYS-Topology optimization process was conducted to reduce weight of the mold. As a result, the set-up time decreased. Consequently, big benefits in terms of cycle time, occupational health and safety, improvement in the process and cost have been achieved.
\end{abstract}

Keywords: ANSYS Static Structural, ANSYS Topology Optimization, Case Study, Kaizen, Process Improvement

\section{Introduction}

In today's conditions, parameters such as production speed, quality, cost and reliability have a great importance in the globalizing producer-consumer society. Process improvements have a critical value for competitive manufacturers, as they reduce cost and waste of time [1]. To improve their processes, manufacturers are inspired by a variety of principles like Kaizen, 6 Sigma and lean manufacturing [2, 3].

Kaizen states that improvement of the process by the manufacturers is as important as the quality of the product. It emphasizes that unknown or uncontrolled parameters are a risk in terms of sustainability of the product quality [4]. Many manufacturers implement improvements by applying the Kaizen principles in their work. Modarress et al. determined a case study and defined Kaizen costs to reduce existing costs of Boeing Commercial Aviation Company, improve quality, and reduce cycle time [5]. Venkataramana et al. studied a case to increase the export prices of crankshaft production, which is the domestic production of an automotive company in India. The production time was decreased by $40 \%$, the production capacity was increased, and production errors were reduced, resulting in a higher customer satisfaction [6]. Kumar et al. investigated the effects of Kaizen on production techniques and delivery times to increase the competition of small-scale industrial organizations in India [7]. Kumar et al. reduced the stock level, delivery time, cycle time by implementing the lean-Kaizen principle in a medium-sized enterprise, thereby achieving improved efficiency and improved product quality [8]. Özdağoğlu et al. studied on reducing the cycle time with Kaizen and lean manufacturing principles of a company producing PVC films [9].

Designers must optimize their designs in today's competitive market in terms of cost and time. For this reason, to survive in competitive and rapidly changing conditions, fast, efficient, functional and cost-effective designs should be introduced in this scope the efficient utilization of CAD and CAE software becomes compulsory. Additionally, topology optimization tools are widely used to improve designs without succumbing to unnecessary design iteration loops. Topology optimization is a useful method to reduce weight 
without endangering safety or strength of the product $[10,11]$. In the literature many topology optimization studies in many diverse applications can be found; some examples are truck chassis, deck lid and undercarriage [12], automotive chassis [13], automotive engine mounts [14], machine tools [15], cast iron feeding system [16], implants [17], [18].

In this study, an air impact wrench is selected to reduce the production cycle time and improve the process ergonomically. The manual mold assembly process is not suitable for hot working conditions of the casting shop due to dependence on manpower. For this reason, the mold geometry has been redesigned to allow the utilization of an air impact wrench. The maximum Vonmises stress (equivalent stress) values of the original geometry and the slotted geometry are compared using at ANSYS - Static Structural software. After the stresses are examined and no risk is found, slots are opened on the actual casting mold. Due to this slotted geometry, the air impact wrench reduces work cycle time by 11 minutes and the workstation is improved ergonomically. Finally topology optimization is conducted on the upper plate of casting mold and Von-Mises stress (Equivalent stress) results of the geometry obtained via topological optimization is examined.

\section{Materials and Methods}

Different sizes of casting molds are used in the casting factories depending on the product and molds on casting machines must be changed in accordance with the demands of production planning. This process is called mold assembly. Safety, set-up time and ergonomics are priorities of the mold assembly process.

The reason for working on the mold assembly station is to provide better working conditions and reduce high cycle time as seen in Figure 1.

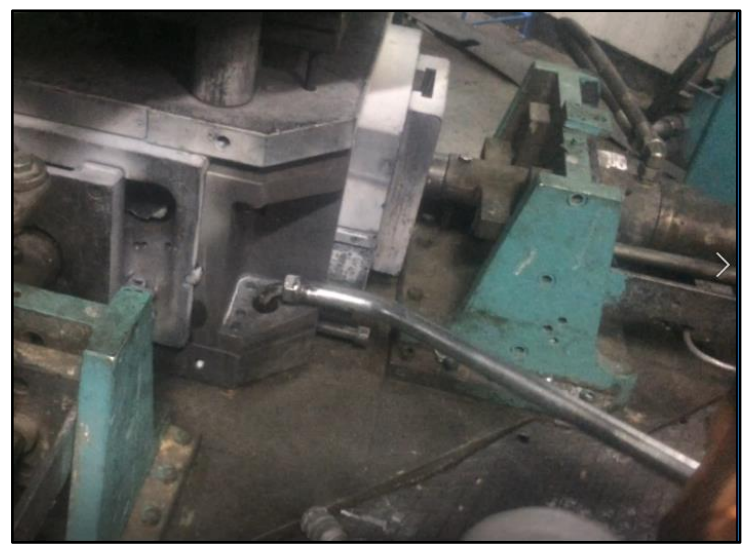

Figure 1. Working conditions and casting mold assembly process

Before making changes on actual casting mold, ANSYS software is used to determine safety risks of the new design by calculating stresses.

In the geometry shown in Figures 2.a and 2.b, structural steel material is used for the lower pusher plate and upper pusher plate, lower plate, upper plate, pillars where the slots are opened, bridge, centering shafts, upper plate dowel pins and centering bushings.

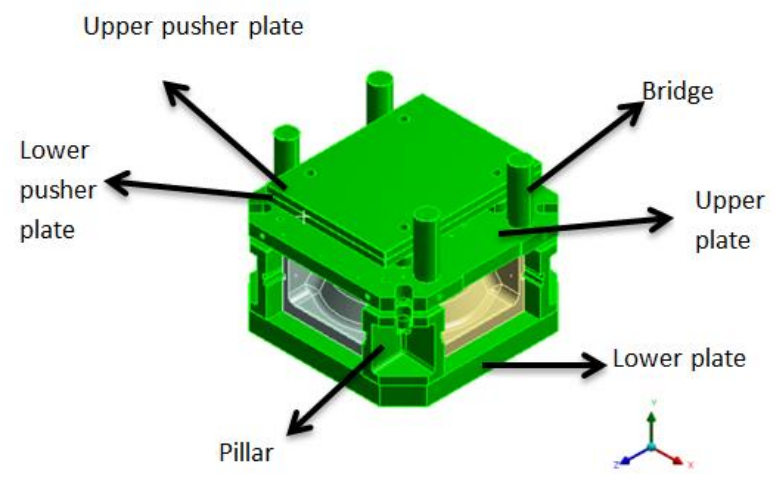

Figure 2.a. The representation of the lower pusher plate and upper pusher plate, lower plate, upper plate, pillars where the slots are opened, bridge.

Table 1. Torque information table required for screwing-loosening the bolt regulated by DIN EN ISO 4014-4018, DIN ISO 262, DIN 34800, DIN EN ISO 4762, DIN EN 20273 standards [19].

\begin{tabular}{|c|c|c|c|c|c|c|c|c|c|c|c|c|c|c|c|}
\hline \multirow[t]{2}{*}{ Size } & \multirow{2}{*}{$\begin{array}{l}\text { Strenght } \\
\text { Class }\end{array}$} & \multicolumn{7}{|c|}{ Assembly preload forces $F_{M T a b}$ in $k N$ for $\mu_{G}=$} & \multicolumn{7}{|c|}{ Tightening torques $\mathrm{M}_{\mathrm{A}}$ in $\mathrm{Nm}$ for $\mu_{\mathrm{K}}=\mu_{\mathrm{G}}=$} \\
\hline & & $\mathbf{0 , 0 8}$ & $\mathbf{0 , 1 0}$ & $\mathbf{0 , 1 2}$ & $\mathbf{0 , 1 4}$ & $\mathbf{0 , 1 6}$ & $\mathbf{0 , 2 0}$ & $\mathbf{0 , 2 4}$ & $\mathbf{0 , 0 8}$ & $\mathbf{0 , 1 0}$ & $\mathbf{0 , 1 2}$ & $\mathbf{0 , 1 4}$ & $\mathbf{0 , 1 6}$ & $\mathbf{0 , 2 0}$ & 0,24 \\
\hline & 8.8 & 107 & 104 & 102 & 99 & 96 & 91 & 85 & 220 & 259 & 295 & 329 & 360 & 415 & 462 \\
\hline M & 10 & 152 & 149 & 145 & 141 & 137 & 129 & 121 & 314 & 369 & 421 & 469 & 513 & 592 & 657 \\
\hline \multirow[t]{2}{*}{18} & 12.9 & 178 & 174 & 170 & 165 & 160 & 151 & 142 & 367 & 432 & 492 & 549 & 601 & 692 & 769 \\
\hline & 8.8 & 136 & 134 & 130 & 127 & 123 & 11 & 109 & 308 & 363 & 415 & 464 & 509 & 588 & 655 \\
\hline M & 10.9 & 194 & 190 & 186 & 181 & 176 & 166 & 156 & 438 & 517 & 592 & 661 & 725 & 838 & 933 \\
\hline 20 & 12.9 & 227 & 223 & 217 & 212 & 206 & 194 & 182 & 513 & 605 & 692 & 773 & 848 & 980 & 1092 \\
\hline
\end{tabular}


Centering bushings

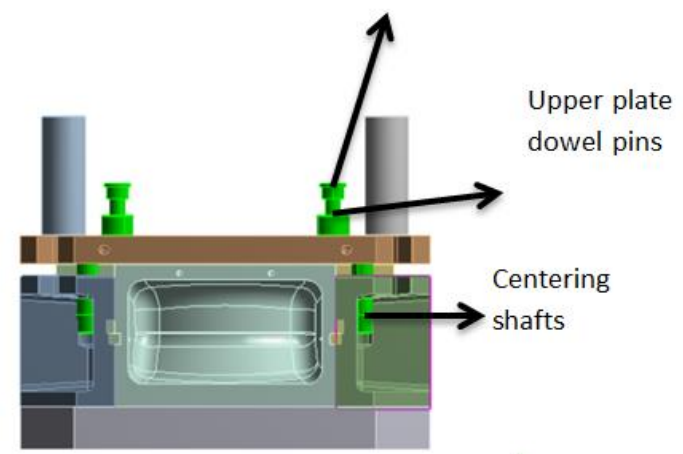

$\stackrel{\circ}{\longleftrightarrow}$

Figure 2.b. The representation of the centering shafts, upper plate dowel pins and centering bushings on the mold geometry.

In the geometry shown in Figure 3.a and 3.b, the side cores materials are cast iron, the upper core is hot work tool steel, and the bottom core is mold cast steel.

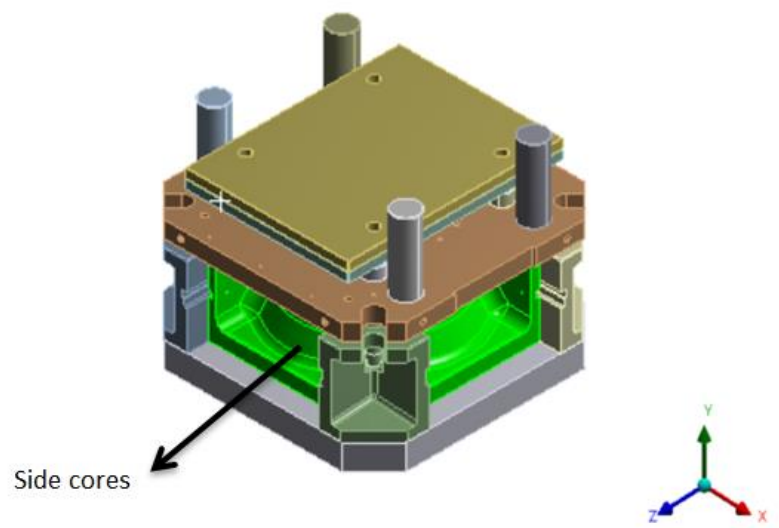

Figure 3.a. The representation of the side cores.

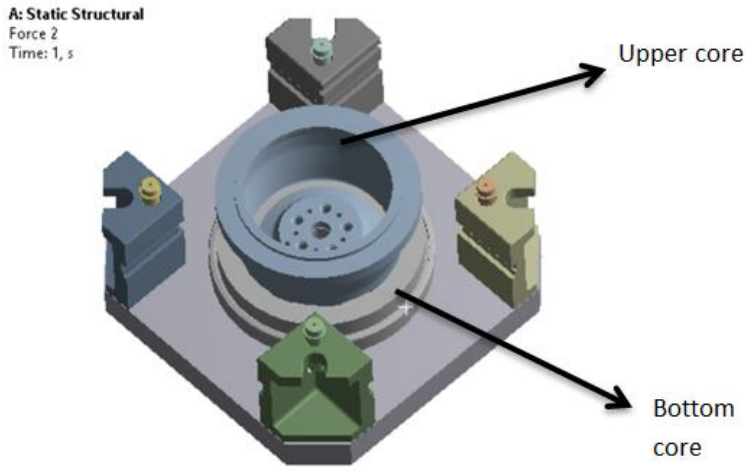

Figure 3.b. The representation of the upper core and bottom core on mold geometry.
After modelling the individual components, the contact conditions are defined. The number of mesh elements is 1.249.023 and the number of nodes is 1.872.114. As boundary conditions, the weights of the upper and lower plates in Figure 5.a were determined to be $1540,8 \mathrm{~N}$. The force of the hydraulic press has been determined to be $62860,6 \mathrm{~N}$ applied to the cylindrical upper surfaces of the bridge elements. As a boundary condition, the surface of the mold that contacts the ground is taken as a fixed support as shown in Figure 4.

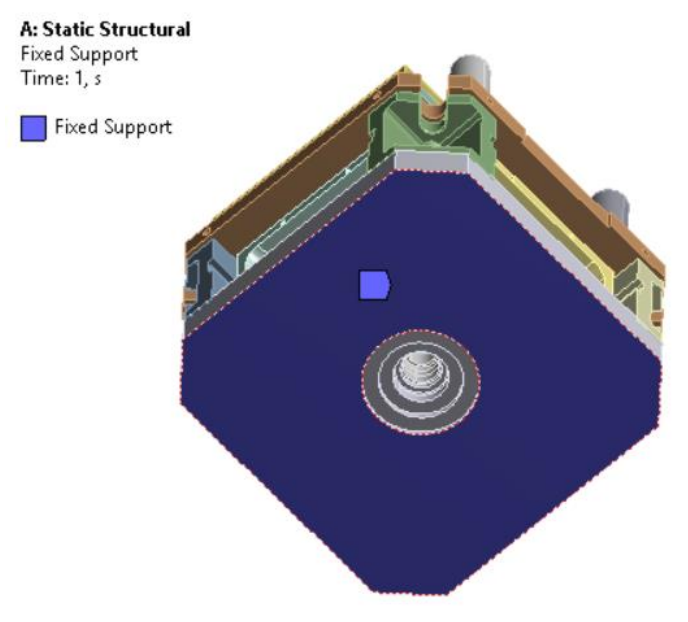

Figure 4. Fixed support surface of the mold that the contacts of the ground.

In order to compare the stress results, the same processes are repeated on the slotted geometry with same boundary conditions as shown in Figure 5.b.

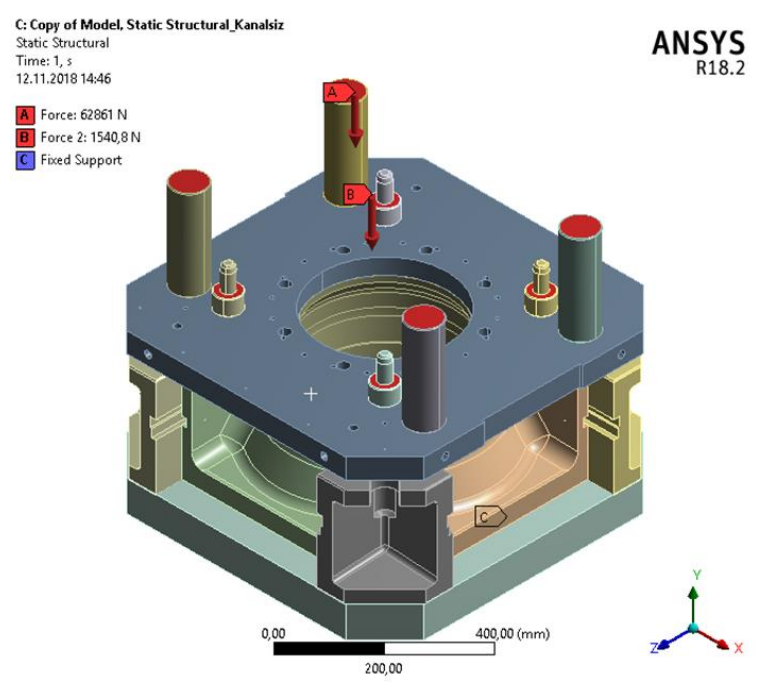

Figure 5.a. Force values shown on original geometry and display of fixed geometry (fixed support). 


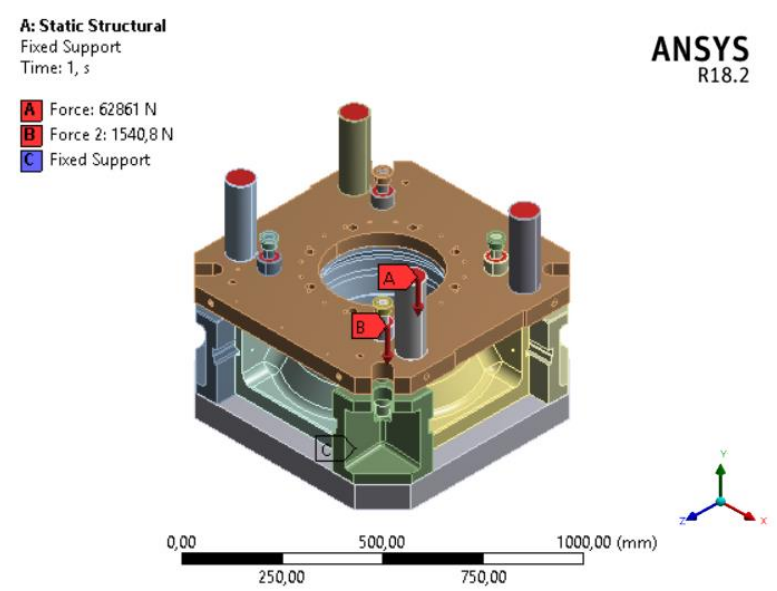

Figure 5.b. Force values shown on slotted geometry and display of fixed geometry (fixed support).

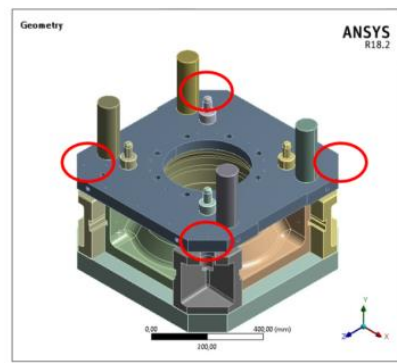

Figure 6.a. 3D geometry in ANSYS.

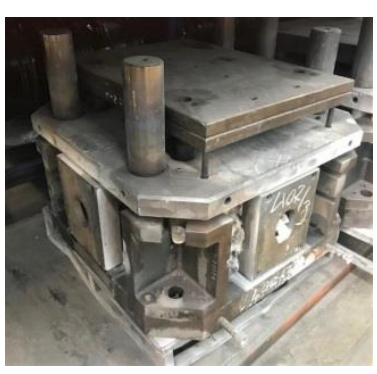

Figure 6.b. Actual view of the mold before revision.
The slots are applied in the red circled corners as shown in Figure 6.a. As seen in Figure 6.b, non-ergonomic condition is encountered during the casting mold assembly. Since the air impact wrench is not physically suitable for the region due to restricted space in the corners of the mold where the assembly process will be performed, it is necessary to implement a slot on the mold corners.

As shown on Figure 7.a and 7.b, certain material removal on the corners are necessary so that the torque wrench can reach bolts, also stud of the torque wrench should be extended for greater length. Air impact wrench has a specified working torque range of 250$1250 \mathrm{Nm}$ to supply $773 \mathrm{Nm}$ of torque as shown in Table 1.

To compare the static stresses on the slotted model, the slotted casting mold geometry is modeled as in Figure 8.a. The operation is carried out on the casting mold upper plate's corner as in Figure 8.b after positive evaluation of Ansys safety examination.

After the slotted geometry is created and the analysis conditions are prepared, topology optimization process is defined on the slotted geometry at ANSYS- Topology Optimization module. The aim of topology optimization is to reduce the amount of raw material during the mold production and to create a lighter upper plate design that supplies the tension values

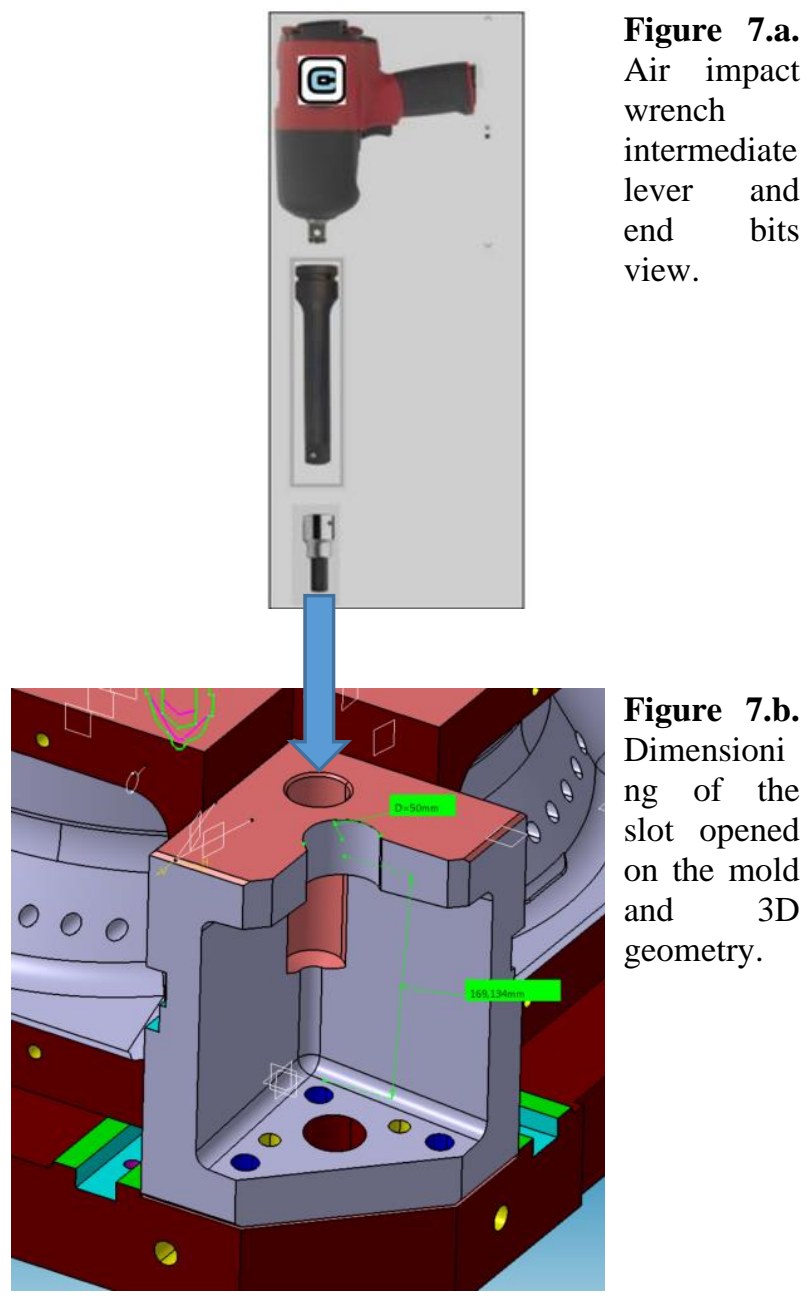

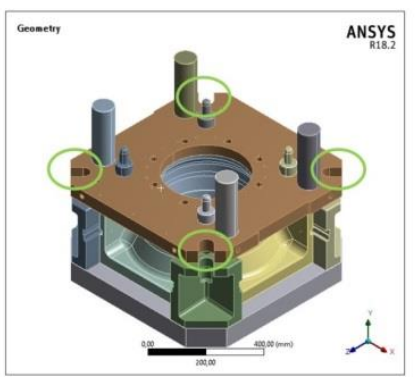

Figure 8.a. 3D geometry in ANSYS.

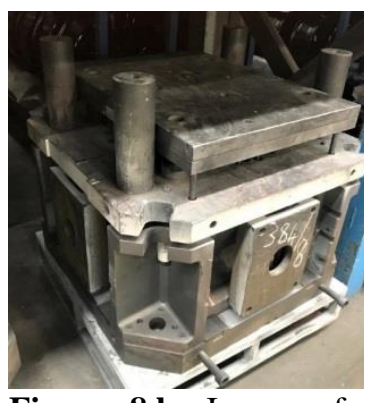

Figure 8.b. Image of the slotted mold.
In this way, the optimum design that will provide a reduction in raw material costs is created.

In order to perform topology optimization, the upper plate is chosen as the region where mass removal will be applied. The solution method is chosen based on the topology optimization as density based [20]. The parameter to be changed on the upper plate is mass, $75 \%$ of the mass is preserved (response constraint). As a result of the change in the mass, static analysis results of slotted and original geometry are examined. Design verification studies are carried out without any financial or time loss thanks to the simulations performed in computer environment [21]. 


\section{Results and Discussion 3.1. Cycle Time Changing}

Before the improvement process, the mold assembly process was 20,3 minutes on average. After improvement, process is decreased to 9,1 minutes on average because of the 6-month project implementation. In this way, the cycle time is reduced by 11,2 minutes as shown in Figure 9.

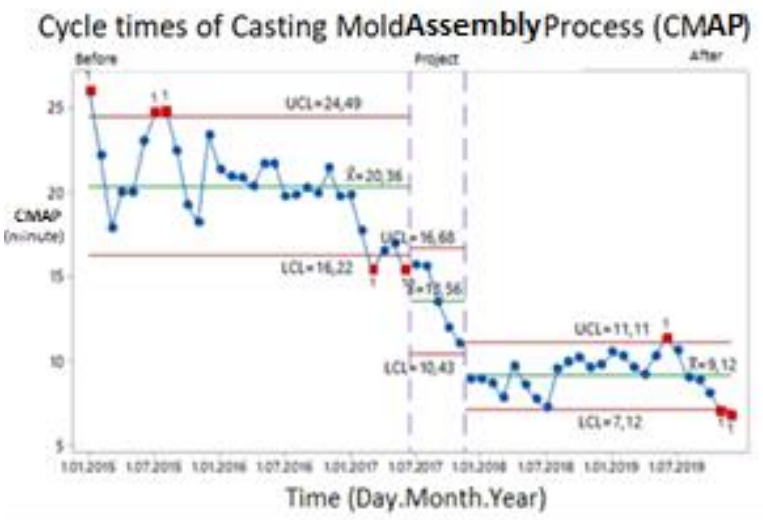

Figure 9. Before and after project cycle times of casting mold assembly process (CMCP)

An average of 11,2 minutes of change in cycle time means that a total of 101,1 minutes of profit is achieved per day in 3 shifts, assuming that an average of 3 molds are changed in the shift. Since the average cycle time of a rim is 330 seconds, it means $101,1 \mathrm{~min} * 60$ seconds / 330 seconds $=18,4$, meaning that there can be approximately 18 additional casting wheels per a day.

\subsection{Slotted Geometry}

The results of the original geometry and slotted upper plate geometry modeled in the ANSYS-Static Structural software are shown in Figure 10.a and 10.b.

In the original geometry shown in Figure 10.a, the maximum Von-Mises stress (Equivalent stress) caused by the boundary and loading conditions of the upper plate is $60,6 \mathrm{MPa}$. The maximum Von-Mises stress (Equivalent stress) caused by the same boundary conditions and load on the upper plate is shown in Figure 10.b and is found to be 46,7 MPa.

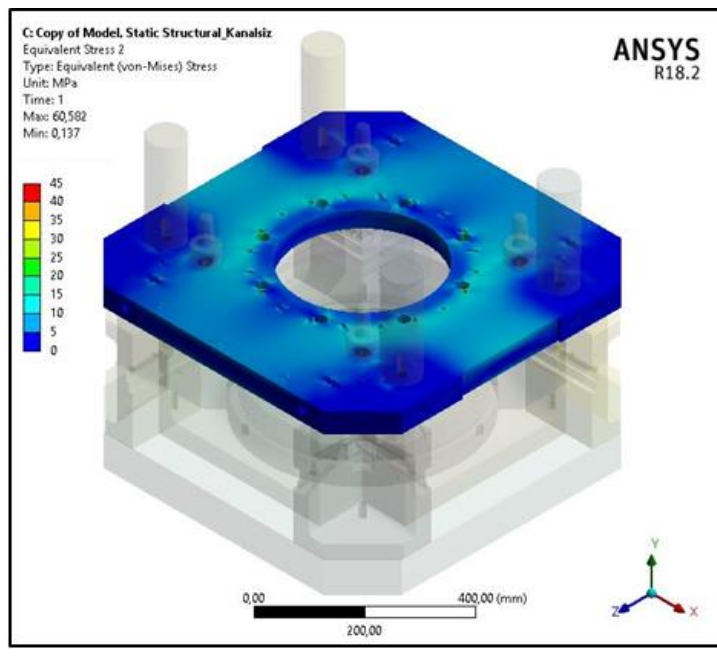

Figure 10.a. Von-Mises stress (Equivalent Stress) results of original geometry

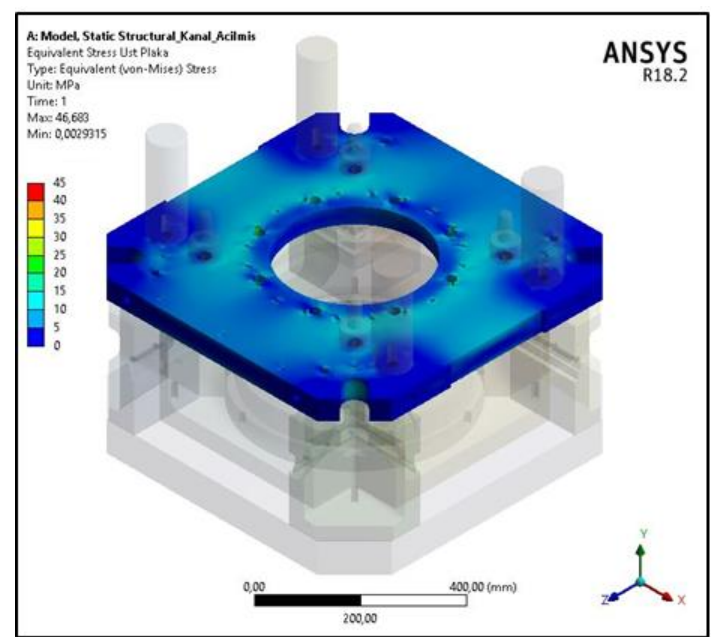

Figure 10.b. Von-Mises stress (Equivalent Stress) results of slotted geometry

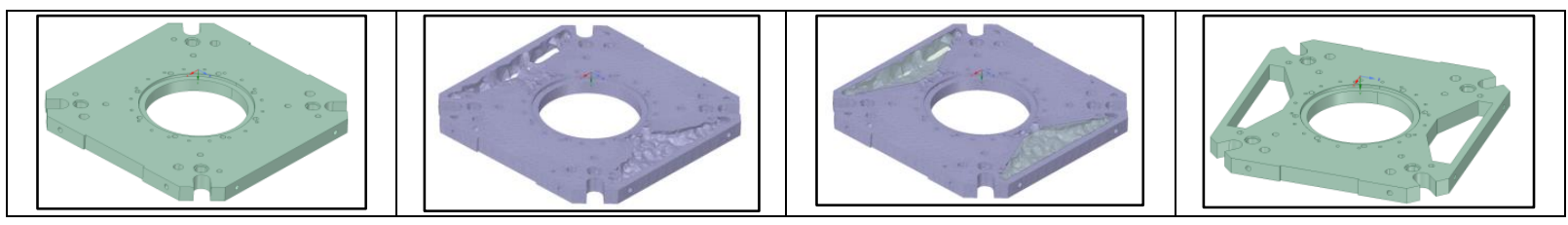

Figure 11. Topology optimization on slotted geometry

As a result, the maximum Von-Mises stress (Equivalent stress) value of the upper plate in slotted geometry is lower than the original geometry. It is concluded that the slot opened on the upper plate can be applied on the

molds according to the static stress value results. In this way, while the stress values are decreasing on the upper plate, the casting mold assembly cycle time has decreased by an average of 11, 2 minutes. So a lighter, more ergonomic, and safer solution was found. 


\subsection{Topology Optimization}

The topology optimization is performed on the upper plate with ANSYS-Topology Optimization module as shown in Figure 11. 25\% of the mass is reduced on the upper plate and a reduction of approximately $31 \mathrm{~kg}$ is achieved after optimizing the upper plate. However static stress values are also critical in the slotted geometry so a new static analysis of the new optimized geometry with the same boundary conditions as before is performed and the results were compared in Figure 12.a and 12.b.

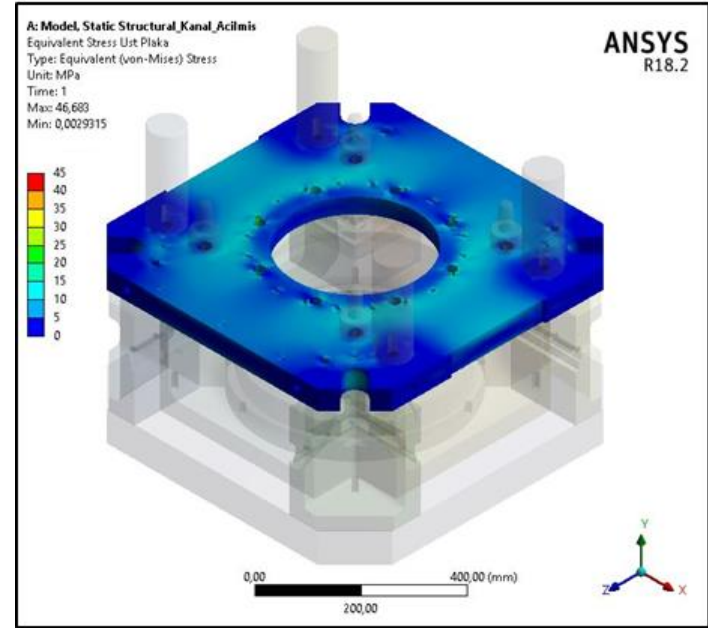

Figure 12.a. Slotted geometry analysis of the upper plate

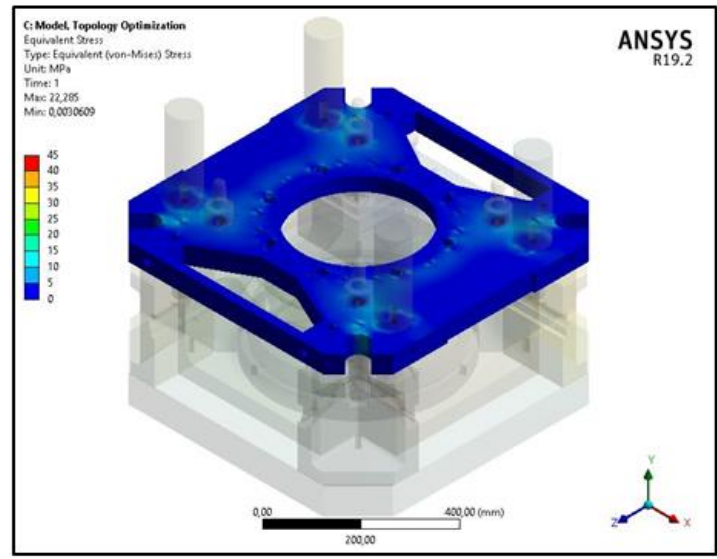

Figure 12.b. Optimized geometry analysis of the upper plate

At a first glance an axisymmetric 4-sided material removal would be expected, but actually the bridges on top of the mold are positioned as a rectangle and are not axisymmetric. As seen in Figure 12.a, under the boundary conditions of the slotted geometry, while the maximum Von-Mises stress (Equivalent Stress) of the upper plate is 46,6 MPa, as seen in Figure 12.b, the maximum Von-Mises stress in the optimized of the upper plate (Equivalent) Stress) is 22,2 $\mathrm{MPa}$. The mass of the upper plate is reduced $31 \mathrm{~kg}$. The decrease in the maximum Von-Mises stress indicates that the optimized upper plate can be used in future mold designs. The decrease in the mass on the upper plate will provide mold casting with less cost and more functionality on the increased wheel dimensions designs.

\section{Discussion}

As a result of the work done,

- Field work was carried out to improve the casting mold assembly process. Air impact wrench was provided to supply the required torque level for the nonergonomic changing procedure with a long cycle time and an improvement was made in the changing procedure.

-Suitable slots for the end bits and intermediate lever were opened in the corners to allow usage of the air impact wrench. After the geometry was slotted, the maximum Von-Mises stresses were taken into consideration. It was concluded that the stress on the upper plate decreased.

- As a result, the cycle time was reduced by 11,2 minutes, saving enough time to produce 18 wheels per day. In this way, the efficiency of the slotted geometry, which had less strain than the original geometry, in the changing process had a positive effect on the annual profit of the company.

- Topology optimization had been made on the upper plate of the casting mold to be produced in the future. $25 \%$ of the upper plate mass was reduced by $31 \mathrm{~kg}$ in total and the maximum Von Mises stress on the upper plate was also reduced. In this way, the cost of raw materials had been reduced and a better mold design had been created in terms of fatigue because of the decrease in tension.

In the future slotted geometry will carry out on casting mold and experimental work will investigate. This geometrical improving may applied to other wheel moulds. This approach may be used for other moulds, equipments and apparatus.

\section{Acknowledgement}

The authors would like to thank Cevher Wheels Company and Numesys Inc. for the permission to publish this article.

\section{Author's Contributions}

Yasemin Nur Aydın: Drafted and wrote the manuscript, performed the experiment and result analysis.

Onur Özaydın: Supervised the experimental and analytical progress, result interpretation and helped in manuscript preparation. 
Alper Akış: Supervised the experimental and analytical progress, result interpretation and helped in manuscript preparation.

\section{Ethics}

There are no ethical issues after the publication of this manuscript.

\section{References}

1. Kabaday1, E. T. 2002. İşletmelerdeki Üretim Performan Ölçütlerinin Gelişimi, Özellikleri ve Sürekli İyileştirme ile İlişkisi. Doğuş Üniversitesi Dergisi; 61-75.

2. Joseph C. Chen, Y. L. 2010. From Value Stream Mapping Toward a Lean/sigma Continuous. International Journal of Production Research; 48: 1069-1086.

3. C-C Wang, K.-S. C.-H.-H. 2010. Application of 6-sigma Design System to Developing an Improvement Model for Multi-process Multi Characteristic. Vol. 225 Part B: J. Engineering Manufacture; 1205-1216.

4. Berger, A. 1997. Continuous improvement and kaizen: standardization and organizational designs. Integrated Manufacturing Systems; 110-117.

5. B. Modarress, A. A. 2005. Kaizen Costing for Lean Manufacturing a Case Study. International Journal of Production Research; 43: 1751-1760.

6. K. Venkataramana, B. R. 2014. Application of Value Stream Mapping for Reduction of Cycle Time in a Machining Process. Procedia Materials Science; 6: 1187 - 1196.

7. Amit Kumar, A. a. 2013. Impacts of Kaizen in a Small-scale Industry of India: a Case Study. International Journal of Lean Six Sigma; 22-45.

8. Sunil Kumar, A. K. 2018. Process Improvement Through LeanKaizen Using Value Stream Map: A Case Study in India. The International Journal of Advanced Manufacturing Technology; 96: $2687-2698$.

9. Aşkın Özdağoğlu, S. R. 2016. Applications of Kaizen and Cycle Time Reduction as Lean Production Techniques in a Semiflexible PVC. Int. Journal of Management Economics and Business;12: 25-37.

10. ANSYS Topology Optimization. 2017. White paper, ANSYS Inc.,Canonsburg, PA U.S.A.; 1-4.

11. Dr.-Ing. Markus Stephan, D.-I. D.-P.-M. 2009. CFD Topology Optimization of Automotive Components. 4th European Automotive Simulation Conference EASC.

12. Chahande, R. Y. 1995. Automotive Applications of Topology Optimization. Structural Optimization; 9: 245-249.

13. Marco Cavazzuti, A. B. 2011. High performance automotive chassis design:. Struct Multidisc Optim; 44: 45-56.

14. Chao Li, I. Y. 2015. Conceptual and Detailed Design of an Automotive Engine Cradle by Using Topology, Shape, and Size
Optimization. Structural and Multidisciplinary Optimization; 51: 547-564.

15. Hüseyin Güçlü YAVUZCAN, M. Ö. 2015. Yatık Ağız Açma Ve Kalibre Etme Makinasının Yapısal Analizi Ve Ağılık Optimizasyonu. Gazi Üniversitesi Fen Bilimleri Dergisi; 3(3): 555-564.

16. R. Tavakoli, P. D. 2009. Optimal Riser Design in Sand Casting Process with Evolutionary Topology oOptimization. Struct Multidisc Optim; 205-214.

17. Vivien J. Challis, A. P.-C. 2010. Prototypes for Bone Implant Scaffolds Designed via Topology Optimization and Manufactured by Solid Freeform Fabrication. ADVANCED ENGINEERING MATERIALS; 12: 1105-1110.

18. Xiaojian Wang, S. X. 2016. Topological Design and Additive Manufacturing of Porous Metals for Bone Scaffolds and Orthopaedic Implants: A Review. Biomaterials; 83: 127-141.

19. Würth Industrie. Dimensioning metric screw assemblies. Wuerth Industrie:https://www.wuerth-

industrie.com/web/media/en/pictures/wuerthindustrie/technikport al/dinokapitel/Kapitel_06_DINO_techn_Teil.pdf

20. M. P. Bendsùe, O. S. 1999. Material Interpolation Schemes in Topology Optimization. Archive of Applied Mechanic; 69: 635654.

21. Nişanci, M.C., Yurddaş, A. 2020. Compare Between the Results of the Casting Simulation and the Results of Experimental Production with Calculating the Interface Heat Transfer Coefficient of the Casting-Mold. Celal Bayar University Journal of Science; Volume 16, Issue 2, 2020, p 169-181 Doi: 10.18466/cbayarfbe.720791. 